\section{Measurement of anthropogenic radionuclides in post-Fukushima Pacific seawater samples}

\author{
Guillaume Lutter, \\ Faidra Tzika, \\ Mikael Hult, \\ Michio Aoyama, \\ Yasunori Hamajima, \\ Gerd Marissens, \\ Heiko Stroh
}

\begin{abstract}
$\overline{\text { Abstract. Following the accident at the Daiichi Fukushima nuclear power plant in 2011, a vast number of Pacific }}$ seawater samples from many locations far from Fukushima have been collected by Japanese investigators. Due to dilution, the activities of radionuclides from North Pacific seawater samples are very low, which calls for extraordinary measures when being measured. This study focuses on the metrological aspects of the gamma-ray spectrometry measurements performed on such samples in two underground laboratories; at HADES (by JRC-IRMM in Belgium), and at Ogoya (by Kanazawa University in Japan). Due to many samples and long measurement times, all available HPGe detectors needed to be employed. In addition to single coaxial detectors, this involved multidetector systems and well detectors. Optimization of detection limits for different radionuclides and detectors was performed using Monte Carlo simulations.
\end{abstract}

Key words: detection limit $\bullet$ Fukushima $\bullet$ gamma-ray spectrometry $\bullet$ Monte Carlo $\bullet$ radiocesium $\bullet$ underground laboratory

G. Lutter, F. Tzika ${ }^{\bowtie}$, M. Hult, G. Marissens, H. Stroh EC-JRC-IRMM,

Retieseweg 111, B-2440 Geel, Belgium,

Tel.: +32 14 571269, Fax: + 3214584273 ,

E-mail: Faidra.Tzika@ec.europa.eu

\section{Aoyama}

Institute of Environmental Radioactivity,

Fukushima University,

1 Kanayagawa, Fukushima, 963-8811 Japan

and Meteorological Research Institute,

1-1 Nagamine, Tsukuba, Ibaraki 305-0052, Japan

Y. Hamajima

Kanazawa University,

O-24 Tatsunokuchi, Nomi, Ishikawa 923-1224, Japan

Received: 24 September 2014

Accepted: 20 May 2015

\section{Introduction}

Following the accident at the Fukushima Daiichi Nuclear Power Plant in March 2011, anthropogenic radionuclides have been released into the North $\mathrm{Pa}$ cific Ocean. Japan has set up a program to monitor these radionuclides over a large part of the North Pacific Ocean by making use of sampling by both research vessels and commercial cargo ships. Sampling of seawater as well as filters for suspended particles, particulate matter, and phytoplankton were performed. The main aims are (i) to study ocean currents, (ii) to study uptake in the food chain, and (iii) to enable more precise calculations of the total release of radioactivity from Fukushima. Except for very near to Fukushima, the activity concentrations of anthropogenic radionuclides (mainly radiocesium) are extremely low. In the central North Pacific, ${ }^{137} \mathrm{Cs}$, for example, has an activity concentration in surface water of a few $\mathrm{mBq} / \mathrm{l}$. As the typical sample volume is 21 , it is clear that extraordinary measures are necessary to monitor these radionuclides. In particular, for gamma-emitting radionuclides, advanced preconcentration techniques combined with measurements in underground laboratories are necessary. A collaboration was established between Joint Research Centre-Institute for Reference Materials and Measurements (JRC-IRMM) and Japan aiming to support organizations in Japan in implementing measurements of radioactivity. In this context, a 
large number (more than 1230, within the first two years) samples were measured using gamma-ray spectrometry in two underground laboratories: (a) the Ogoya Underground Laboratory (OUL) operated by Kanazawa University and (b) the HADES Underground Laboratory located at the site of the Belgian Nuclear Research Center SCK • CEN in Mol, Belgium and where JRC-IRMM operates an ultra low-level radioactivity laboratory. This work discusses the metrological aspects like establishing equivalence in quantitative output, selection of detectors, and optimization of detection efficiencies with respect to the specifications of the samples and the aimed detection limits.

\section{Method}

\section{Samples}

The most common type of sample in this investigation is preconcentrated seawater. Most samples are from surface water but at some locations, depth profiles down to $600 \mathrm{~m}$ have been collected. The 2-l water samples were treated using an extensive preconcentration procedure developed by Aoyama and Hirose $[1,2]$. The procedure, in its first phase, is using ammonium phosphomolybdate (AMP) to adsorb Cs. As the AMP retains a small part of potassium (including ${ }^{40} \mathrm{~K}$ ), a second phase is sometimes deemed necessary. The key step in the second phase involves extracting $\mathrm{Cs}$ by producing a precipitate of $\mathrm{Cs}_{2} \mathrm{PtCl}_{6}$ by adding chloroplatinic acid. The final sample from the first preconcentration phase is about $4 \mathrm{~g}$ of yellowish powder. This is transferred to a Teflon vial with an inner diameter of $1.4 \mathrm{~cm}$ (Fig. 1). Figure 1 also shows one similar vial containing a filter with organic matter and phytoplankton (mass about $1 \mathrm{~g}$ ) and one with material from a sediment trap, that is, filters with particulate matter (mass less than $1 \mathrm{~g}$ ).

\section{The Ogoya Underground Laboratory}

The Ogoya Underground Laboratory (OUL), which is part of the Low Level Radioactivity Laboratory

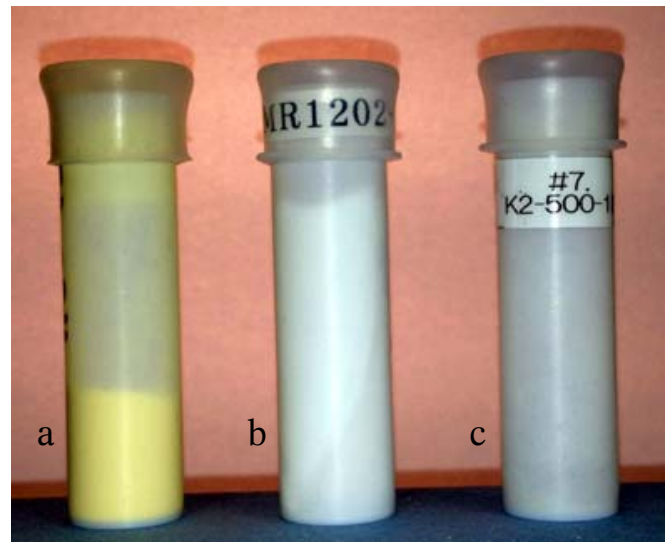

Fig. 1. Photo of typical samples in Teflon vials: (a) seawater precipitate obtained using ammonium phosphomolybdate (AMP), (b) filters with organic matter and phytoplankton, (c) particulate matter.
(LLRL) of Kanazawa University, was constructed in the tunnel of the former Ogoya copper mine. It is located about $20 \mathrm{~km}$ from the LLRL with an overburden of about $135 \mathrm{~m}$ of rock. It started operations in 1995 [3]. The OUL operates 18 ultra low-background HPGe detectors, as of April 2008 [4]: one coaxial-type (relative efficiency 94\%), eleven well-type (relative efficiencies of 36-73\%), and six planar-type Ge (relative efficiencies of 18-34\%). All detectors are specially designed for low-background counting. They are housed in a $20 \mathrm{~cm}$ lead-equivalent outer shielding and a 3-5 cm lead inner shielding. The latter is made of ultra low-background lead prepared from old roof tiles of Kanazawa Castle. The background integrated count rate $(50-2000 \mathrm{keV})$ ranges from $690-4000 \mathrm{~d}^{-1}$ for the different detectors. Details of some of detectors' performance are given by Hamajima and Komura [5]. At OUL, a large number of low-level radioactivity measurements have been performed over the years [6].

\section{The HADES Underground Laboratory}

The HADES Underground Laboratory is operated by the organization Euridice and is located on the site of the Belgian Nuclear Centre SCK •CEN. It is constructed $225 \mathrm{~m}$ underground in the middle of a 100 -m thick clay layer. JRC-IRMM is renting a part of the laboratory for performing ultra low-level radioactivity measurements [7]. For the moment, 11 HPGe detectors made from specially selected radiopure materials are in operation. JRC-IRMM performs reference measurements in a wide range of areas and therefore, the HPGe detectors are of different types. The detectors comprise (relative efficiency within brackets): 1 small planar (8\%) n-type with excellent resolution, 2 thick planar (20 and 50\%) so-called BeGe, 1 coaxial $(60 \%), 1$ coaxial with thin dead layer $(106 \%)$ so-called XtRa and 3 multidetector systems. The Sandwich detector system [8] is composed of a coaxial detector (80\%) and a second coaxial detector $(90 \%$ with thin dead layer) that has an inverted arm so that the endcap is 'looking' down towards the first detector. The Pacman detector system [9] is composed of an n-type coaxial detector $(62 \%)$ a so-called REGe, and a coaxial (90\%) detector above it, which is looking down just like in the case of the Sandwich detector. The third multidetector system is composed of a well crystal below which is a second small planar crystal within the same cryostat. A new high-resolution well-type detector has been procured and should be operational in 2015. The background integrated count rate $(50-2000 \mathrm{keV})$ ranges from 130 to $900 \mathrm{~d}^{-1}$ for the different detectors.

\section{Monte Carlo simulations}

The Monte Carlo code EGSnrc [10] was used for calculating efficiencies for different sample/detector/radionuclide configurations in this study. The computer models of the detectors have been developed by using physical dimensions provided by 
manufacturers and extracted from radiographs. The dead layer thicknesses (that differ from one crystal surface to another) have been adopted by adjusting the thicknesses in the model until good (generally, better than 5\%, often better than 3\%) agreement between measured efficiencies and calculated efficiencies was obtained [11, 12]. With the aim to have a counting statistical uncertainty below $1 \%$ for the main gamma lines, typically $10^{7}$ histories were generated in the Monte Carlo simulations.

\section{Validation of procedure}

In both laboratories, calibration standards made from standardized liquid solutions were prepared in the vials used for the samples. In order to validate the procedures and to ensure comparability of results between Ogoya and HADES, radiocesium containing samples made from IAEA reference material 443 (Irish Sea water) and 445 (spiked tap water) were prepared and measured in both laboratories. The procedure for preparing the reference samples was identical to the procedure for the pre-concentration of the Pacific seawater. The results of the validation measurements showed an agreement with the calculated full energy peak efficiencies between 0.2 and $11 \%$ depending on the detector. The precision was somewhat better for ${ }^{137} \mathrm{Cs}$ than for ${ }^{134} \mathrm{Cs}$ and was (for both radionuclides) adequate for this work as the samples had low activities and generally, the counting statistics was the major source of uncertainty.

\section{Optimization of the measurements}

The requested detection limit for the measurements in HADES was $0.5 \mathrm{mBq}$ for ${ }^{134} \mathrm{Cs}$ and ${ }^{137} \mathrm{Cs}$. To reach this target, the following elements are necessary (i) a low-background environment, (ii) optimization of the detection efficiency, and (iii) reduction of the ${ }^{40} \mathrm{~K}$ intrinsic activity.

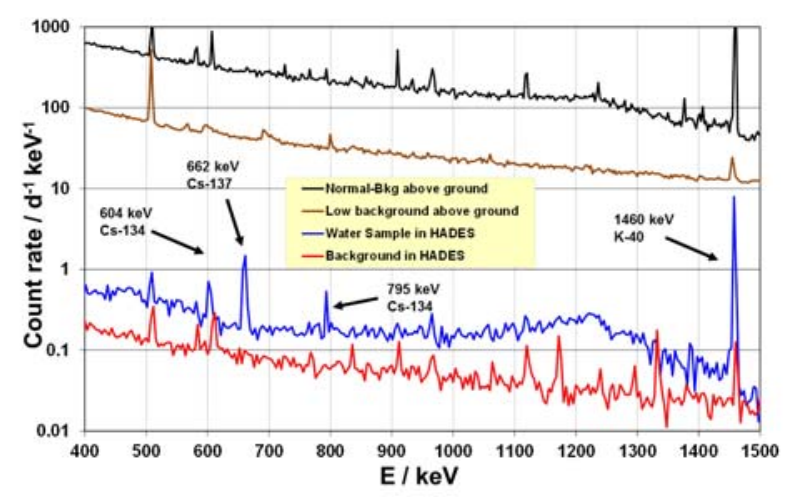

Fig. 2. Spectrum from a 4-g Pacific seawater precipitate sample, measured in HADES (using the Pacman system [9]), compared to the background (from other detectors) as measured above and underground. The activities (measured in 2013) for ${ }^{134} \mathrm{Cs},{ }^{137} \mathrm{Cs}$, and ${ }^{40} \mathrm{~K}$ are respectively $1.2 \mathrm{mBq}, 2.5 \mathrm{mBq}$, and $230 \mathrm{mBq}$.

\section{Background reduction}

The comparison of the background measurements (Fig. 2) with the spectrum from a 4-g Pacific seawater precipitate containing $1.2 \mathrm{mBq}{ }^{134} \mathrm{Cs}, 2.5 \mathrm{mBq}$ ${ }^{137} \mathrm{Cs}$, and $230 \mathrm{mBq}{ }^{40} \mathrm{~K}$, shows that the sample is unsuitable for measurement above ground. The measured background count rate above ground of a low-background HPGe detector is two orders of magnitude higher than the count rate measured in the sample. As OUL is located at a more shallow depth than HADES, the background in HADES is lower than in OUL. Therefore, the samples with the lower activities were sent for measurement to JRC, where the lowest activity ones were measured using the multidetector systems.

\section{Detection efficiency}

The original vials (Fig. 1) are suitable for placement in a well detector like the 11 detectors in the Ogoya laboratory. This is a perfect geometry for measuring ${ }^{137} \mathrm{Cs}$. However, for radionuclides with cascading gamma rays like ${ }^{134} \mathrm{Cs}$ and ${ }^{110 \mathrm{~m}} \mathrm{Ag}$, the occurrence of a high number of true summing coincidences reduces the size of the full energy peaks (FEP). In some cases, the so-called sum-peak is greater than the corresponding FEP in spectra collected using a well detector. Another option is to use multicrystal detectors collecting separate spectra or operating in anti-coincidence mode. This is possible with the Sandwich and Pacman detector systems in HADES. The vial geometry is optimal for well detectors but for other detectors, a more suitable geometry for optimizing detection efficiency is disc-shaped samples. For some samples measured on coaxial detectors, it was considered unsuitable to move the material, so the material was left in the original Teflon vial and measured either standing up (Fig. 3a) or laying down (Fig. 3b) on the endcap of a detector. For other samples, the water precipitate was transferred to a small disc-shaped container (internal height: $3.5 \mathrm{~mm}$, internal diameter: $50 \mathrm{~mm}$ ) (Fig. 3c). These different configurations were studied using Monte Carlo simulations.

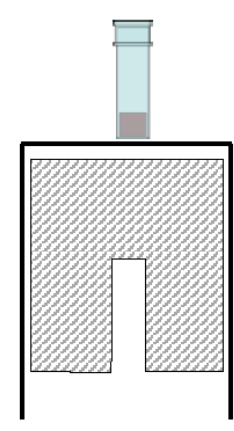

(a)

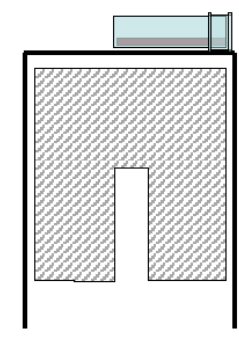

(b) vial laying

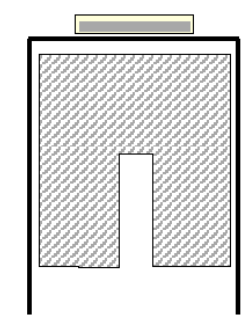

(c)

Fig. 3. Schematic drawings of three sample geometries with the same amount of water powder on a $106 \%$ relative efficiency coaxial HPGe detector. 


\section{${ }^{40} \mathrm{~K}$ reduction}

The intrinsic activity of ${ }^{40} \mathrm{~K}$ increases the continuum in the different regions of interest (ROI) due to Compton scattering of the $1460 \mathrm{keV}$ gamma-line and consequently, increases the minimum detectable activity (MDA). In order to study this effect, the MDAs were calculated for ${ }^{137} \mathrm{Cs}$ in a 4-g water precipitate, measured in HADES on the well detector named 'Ge-12' ( $2 \mathrm{~kg}$ crystal), as a function of measurement time for different intrinsic activities of ${ }^{40} \mathrm{~K}$. The MDAs $(\alpha=$ 0.05) were calculated following the ISO11929-3:2000 standard. The considered activities of ${ }^{40} \mathrm{~K}$ were the natural activity contained in 21 of seawater $(30 \mathrm{~Bq})$, the expected activity of ${ }^{40} \mathrm{~K}$ after the first phase of the pre-concentration procedure using AMP $(0.3 \mathrm{~Bq})$, the possible maximum activity after a second stage of treatment using chloroplatinic acid $(0.03 \mathrm{~Bq})$, and the case of no ${ }^{40} \mathrm{~K}$ present. It is noted that not all samples are treated with the chloroplatinic acid as the work is time-consuming and the chemicals expensive. The background counts in the ROI of the ${ }^{137} \mathrm{Cs}$ peak, which was used in the calculation of the shown MDAs, were calculated as the sum of three components within the respective ROI: (a) ${ }^{137} \mathrm{Cs}$ net peak counts in the background spectrum, zero in our case, (b) the continuum in a measured background spectrum, and (c) the continuum in a simulated spectrum from a sample containing ${ }^{40} \mathrm{~K}$ using Monte Carlo.

\section{Results and discussion}

\section{Detection limits and efficiencies for a coaxial Ge crystal}

In the case of a 4-g seawater precipitate, the Monte Carlo simulations show that for a coaxial HPGe detector (106\% relative efficiency), the disc geometry gives the optimal FEP efficiencies for the ${ }^{137} \mathrm{Cs}$, ${ }^{134} \mathrm{Cs}$, and ${ }^{110 \mathrm{~m}} \mathrm{Ag}$ radionuclides (Table 1 ). If the sample has to stay in the original vial, placing the vial horizontally on the endcap of the detector gives the best results. For calculation of the MDAs shown in Table 1, we considered the measured background of the detector 'Ge-4' in HADES [13] and added a Monte Carlo simulated contribution from $300 \mathrm{mBq}$ ${ }^{40} \mathrm{~K}$ in the sample under the peaks of ${ }^{137} \mathrm{Cs},{ }^{134} \mathrm{Cs}$, and ${ }^{110 \mathrm{~m}} \mathrm{Ag}$. As the MDA depends mainly on the FEP efficiency and the background, the shown MDA comparison, calculated for a 7-day measurement, gives the same conclusion as for the FEP efficiencies.

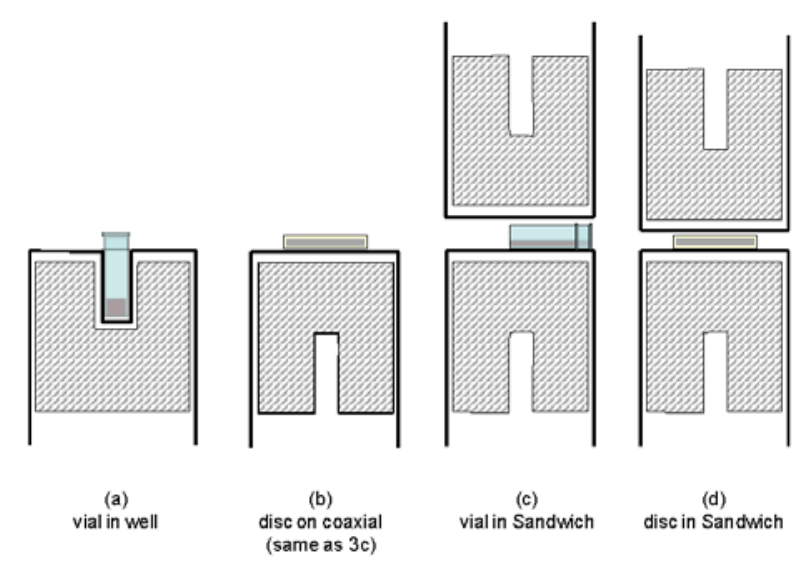

Fig. 4. Four configurations for measuring $4 \mathrm{~g}$ of seawater precipitate: (a) a vial inside a 2-kg well detector (Ge-12 in HADES), (b) a disc on a $2.1 \mathrm{~kg}$ coaxial detector $(\mathrm{Ge}-4$ in HADES [13]), (c) a vial in the Sandwich detector [8], and (d) a disc in the Sandwich detector.

\section{Detection limits and efficiencies for different detection systems}

The same study as in the previous paragraph was done with different detector configurations available in HADES as depicted in Fig. 4. The results are presented in Table 2. The well detector (the main detector type at OUL) gives the best FEP efficiency and MDA for a radionuclide that is not subjected to coincidence summing (e.g. ${ }^{137} \mathrm{Cs}$ ). However, for the measurement of ${ }^{134} \mathrm{Cs}$ and ${ }^{110 \mathrm{~m}} \mathrm{Ag}$, the multicrystal detector system called 'Sandwich' gives better performance than the well detector. In the case of the well detector, despite the higher detection efficiency, the FEP efficiency is reduced due to the crystal geometry that enhances the coincidence summing effect.

For high activity samples, it is common to operate multidetector systems in coincidence mode. This is not an option for low-level samples as the count rate is too low. However, operating multidetector systems in anti-coincidence mode is often an efficient way of reducing the background from, for example, Compton scattering from ${ }^{40} \mathrm{~K}$. From the data in Table 2, one can conclude that two HPGe detectors, such as in Fig. 4c-d, are not very efficient for Compton suppression. The effect on the ${ }^{137} \mathrm{Cs} \mathrm{MDA}$ is a very marginal improvement and for ${ }^{134} \mathrm{Cs}$, it is even worse (due to cascading gamma rays) as some events giving rise to a count in the FEP are removed. Another factor affecting the detection limits is the

Table 1. FEP efficiencies and MDAs for ${ }^{137} \mathrm{Cs},{ }^{134} \mathrm{Cs}$ and ${ }^{110 \mathrm{~m}} \mathrm{Ag}$ for different sample configurations for the coaxial $\mathrm{HPGe}$ detector (Ge-4) with 106\% relative efficiency. The MDA calculation $(\alpha=0.05)$ is following the ISO11929-3:2000 standard and a 7-day measurement with a $4 \mathrm{~g}$ sample containing $300 \mathrm{mBq}{ }^{40} \mathrm{~K}$

\begin{tabular}{lcccccccc}
\hline \multirow{2}{*}{ Sample } & \multicolumn{4}{c}{ FEP efficiency [\%] } & \multicolumn{3}{c}{ MDA [mBq] } \\
\cline { 2 - 10 } & ${ }^{137} \mathrm{Cs}$ & \multicolumn{2}{c}{${ }^{134} \mathrm{Cs}$} & ${ }^{110 \mathrm{~m}} \mathrm{Ag}$ & ${ }^{137} \mathrm{Cs}$ & \multicolumn{2}{c}{${ }^{134} \mathrm{Cs}$} & ${ }^{110 \mathrm{~m}} \mathrm{Ag}$ \\
\cline { 2 - 10 } & $662 \mathrm{keV}$ & $604 \mathrm{keV}$ & $795 \mathrm{keV}$ & $657 \mathrm{keV}$ & $662 \mathrm{keV}$ & $604 \mathrm{keV}$ & $795 \mathrm{keV}$ & $657 \mathrm{keV}$ \\
\hline Vial standing (Fig. 3a) & 6.57 & 5.18 & 4.47 & 4.05 & 0.49 & 0.53 & 0.62 & 0.74 \\
Vial lying (Fig. 3b) & 7.94 & 6.00 & 5.10 & 4.50 & 0.42 & 0.48 & 0.57 & 0.69 \\
Disc (Fig. 3c) & 8.68 & 6.43 & 5.41 & 4.75 & 0.39 & 0.45 & 0.55 & 0.66 \\
\hline
\end{tabular}

FEP: Full energy peak. MDA: Minimum detectable activity. 
Table 2. FEP efficiencies and MDAs for ${ }^{137} \mathrm{Cs},{ }^{134} \mathrm{Cs}$, and ${ }^{110 \mathrm{~m}} \mathrm{Ag}$ for different sample/detector configurations. The MDA calculation $(\alpha=0.05)$ is following the ISO11929-3:2000 standard and a 7-day measurement with a $4 \mathrm{~g}$ sample containing $300 \mathrm{mBq}{ }^{40} \mathrm{~K}$

\begin{tabular}{lcccccccc} 
& \multicolumn{3}{c}{ FEP efficiency [\%] } & \multicolumn{4}{c}{ MDA [mBq] } \\
\cline { 2 - 8 } Case & \multicolumn{1}{c}{${ }^{137} \mathrm{Cs}$} & \multicolumn{2}{c}{${ }^{134} \mathrm{Cs}$} & ${ }^{110 \mathrm{~m}} \mathrm{Ag}$ & ${ }^{137} \mathrm{Cs}$ & ${ }^{134} \mathrm{Cs}$ & ${ }^{110 \mathrm{~m}} \mathrm{Ag}$ \\
\cline { 2 - 9 } & $662 \mathrm{keV}$ & $604 \mathrm{keV}$ & $795 \mathrm{keV}$ & $657 \mathrm{keV}$ & $662 \mathrm{keV}$ & $604 \mathrm{keV}$ & $795 \mathrm{keV}$ & $657 \mathrm{keV}$ \\
\hline 4a) & 20.0 & 8.3 & 6.6 & 4.0 & 0.26 & 0.52 & 0.73 & 1.07 \\
(Fig. 4b) & 8.7 & 6.4 & 5.4 & 4.8 & 0.39 & 0.45 & 0.55 & 0.66 \\
aying (Fig. 4c) & 10.2 & 8.5 & 7.1 & 6.7 & 0.45 & 0.51 & 0.64 & 0.59 \\
laying anti-coinc. & 10.2 & 6.5 & 5.5 & 4.2 & 0.42 & 0.62 & 0.81 & 0.87 \\
(Fig. 4d) & 14.0 & 10.6 & 8.9 & 7.9 & 0.35 & 0.43 & 0.55 & 0.55 \\
anti-coinc. & 14.0 & 7.2 & 6.0 & 4.0 & 0.33 & 0.60 & 0.80 & 1.00 \\
\hline
\end{tabular}

FEP: Full energy peak. MDA: Minimum detectable activity.

resolution. Generally, for bigger detectors, planar crystals with point contacts have the best resolution followed by coaxial detectors, while well detectors have the worst resolution. One can roughly say that there is a $20 \%$ difference in resolution in each step, which directly affects the detection limits. These aspects were, however, not included in Table 2.

\section{Effect of ${ }^{40} \mathrm{~K}$ on the detection limits}

Figure 5 shows the calculated MDA for ${ }^{137} \mathrm{Cs}$ in a 4-g water precipitate, measured in HADES on the well detector named 'Ge-12' (2 kg crystal), as a function of measurement time for different intrinsic activities of ${ }^{40} \mathrm{~K}$. It may be observed that after 7 days of measurement, an MDA of $0.26 \mathrm{mBq}$ can be reached for the AMP pre-concentrated sample $\left({ }^{40} \mathrm{~K}\right.$ of $300 \mathrm{mBq}$ ). A sample, which underwent the second phase of the treatment $\left({ }^{40} \mathrm{~K}\right.$ of $\left.30 \mathrm{mBq}\right)$, will give an MDA of $0.16 \mathrm{mBq}$. The calculation shows that if a lower MDA is needed for a given sample, which has only been treated with the first phase, one can increase the measurement time to about 3 weeks to obtain a similar MDA given that the general detector background is sufficiently low.

\section{Impact on oceanography}

The data collected in this project can be used to study many features in the oceans. It is, for example, of interest to study the changes with time of currents and the distribution of radionuclides in the ocean. Therefore, work is ongoing on pursuing further sampling campaigns and measurements. One example of the oceanographic analysis is the study of a mesoscale eddy current appearing in the near costal region just south of Fukushima that may prevent occasionally the flow of water to the south [14]. This had not been studied before. Furthermore, the intense sampling in 2011 and 2012 revealed that the main body of the radioactivity released from Fukushima traveled near the surface towards the east along $40^{\circ} \mathrm{N}$ with a speed of about $8 \mathrm{~cm} / \mathrm{s}$. At the location near the Date Line $\left(180^{\circ} \mathrm{E}\right)$, a subsurface maximum of ${ }^{134} \mathrm{Cs}$ and ${ }^{137} \mathrm{Cs}$ from Fukushima has been found at a depth of $400 \mathrm{~m}$. This is due to subduction, which impedes distribution further east [15]. Detailed results of these measurements and the oceanographic implications are presented in other articles (see e.g. [14-17]) and are planned to be published in upcoming papers.

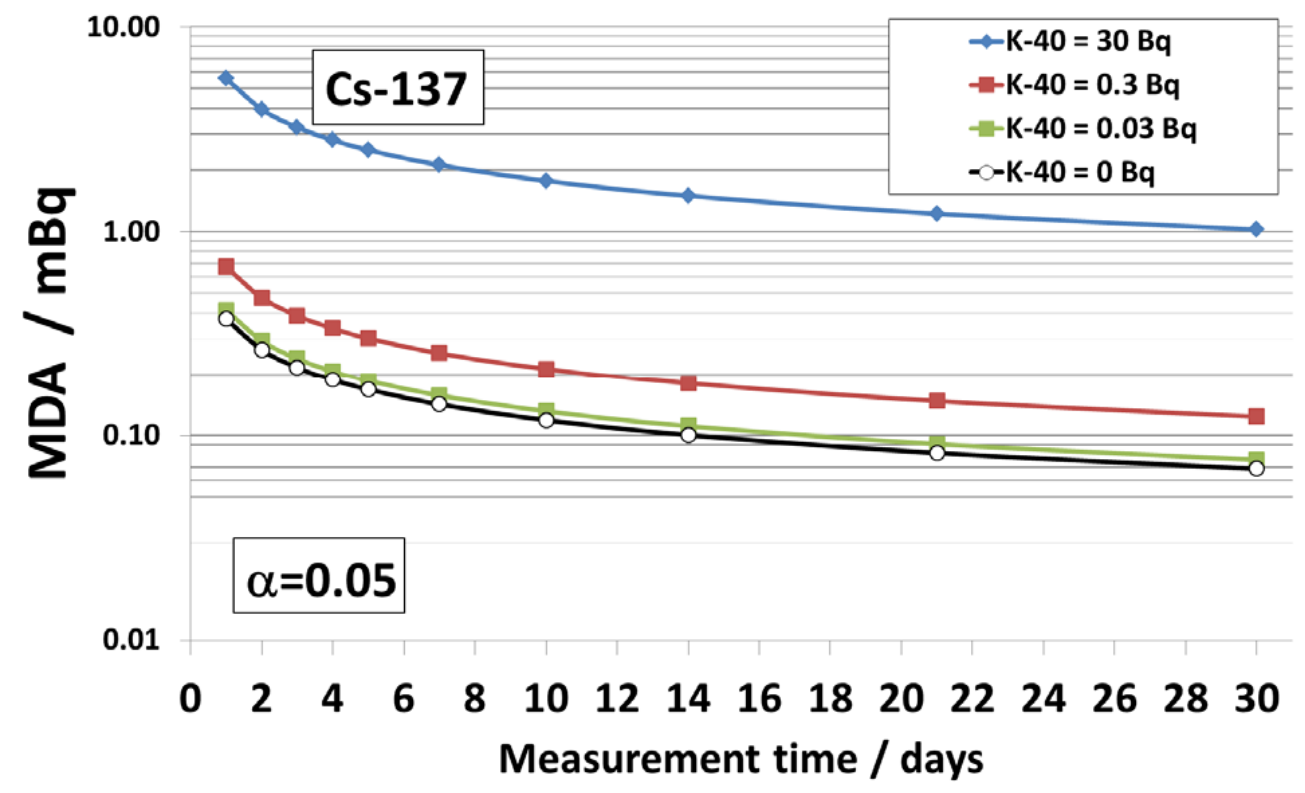

Fig. 5. Detection limits (MDA) for ${ }^{137} \mathrm{Cs}$ in a 4-g seawater precipitate sample, measured in a 2-kg well detector (Ge-12 in HADES), as a function of measurement time for different activities of ${ }^{40} \mathrm{~K}$ in the sample. 


\section{Discussion and conclusions}

Measurements of activities in the order of $1 \mathrm{mBq}$ require long measurement times (several days) and detectors with very low background. There is a limited number of such detectors available, so collaboration in the field of underground gamma-ray spectrometry is a very efficient way of coping with temporary high workloads. This study shows that it is possible to obtain robust results from measurements of similar samples using many detectors of different configurations. It is important to consider metrological aspects carefully when many detectors and laboratories measure samples from, for example, one depth profile of radioactivity in seawater. To save time and resources, the 'best' detectors are used for samples with very low activities and detectors with lower efficiencies and higher background are used for samples containing the highest activities. In this context, Monte Carlo simulations play an important role to optimize planning and distribution of samples to laboratories and detectors.

Acknowledgments. The work of the Euridice staff of $\mathrm{SCK} \cdot \mathrm{CEN}$ is gratefully acknowledged.

\section{References}

1. Hirose, K., Aoyama, M., Igarashi, Y., \& Komura, K. (2005). Ultra-sensitive mass spectrometric and other methods applied to environmental problems. J Radioanal. Nucl. Chem., 263, 349-353.

2. Aoyama, M., \& Hirose, K. (2007). Radiometric determination of anthropogenic radionuclides in seawater. In P. Povinec (Ed.), Analysis of environmental radionuclides (pp. 137-162). Hungary: Elsevier.

3. Komura, K. (1998). Challenge to detection limit of environmental radioactivity. In Y. Ogawa \& $\mathrm{T}$. Tsujimoto (Eds.), Proceedings of the 1997 International Symposium on Environmental Radiation (pp. 56-75). Osaka, Japan: Kansai Kosaido Co.

4. Kanazawa University. (2014). Detectors in the Ogoya Underground Laboratory. Retrieved October 1st, 2014, from http://llrl.ku-unet.ocn.ne.jp/oul/sub9. html.

5. Hamajima, Y., \& Komura, K. (2004). Background components of Ge detectors in Ogoya Underground Laboratory. Appl. Radiat. Isot., 61, 179-183.

6. Komura, K., \& Hamajima, Y. (2004). Ogoya Underground Laboratory for the measurement of extremely low levels of environmental radioactivity: review of recent projects carried out at OUL. Appl. Radiat. Isot., 61, 185-189.

7. Andreotti, E., Hult, M., Gonzalez de Orduña, R., Marissens, G., Mihailescu, M., Wätjen, U., \& Van Marcke, P. (2011). Status of underground radioactivity measurements in HADES. In 3rd International Conference "Current Problems in Nuclear Physics and Atomic Energy", 7-12 June 2010 (pp. 601-605). Ukraine: Publishing Department of KINR.

8. Wieslander, J. S. E., Hult, M., Gasparro, J., Marissens, G., Misiaszek, M., \& Preusse, W. (2009). The sandwich spectrometer for ultra-low-level $\gamma$-ray spectrometry. Appl. Radiat. Isot., 67, 731-735.

9. Lutter, G., Hult, M., Marissens, G., Andreotti, E., Rosengård, U., Misiaszek, M., Yüksel, A., \& Sahin, N. (2013). A new versatile underground gamma-ray spectrometry system. Appl. Radiat. Isot., 81, 81-86.

10. Kawrakow, I. I., Mainegra-Hing, E., Rogers, D. W. O., Tessier, F., \& Walters, B. R. B. (2011). The EGSnrc Code System: Monte Carlo simulation of electron and photon transport (4th printing). Ottawa, Canada: National Research Council of Canada. (Technical Report PIRS-701).

11. Gasparro, J., Hult, M., Johnston, P. N., \& Tagziria, H. (2008). Monte Carlo modelling of Germanium crystals that are tilted and have rounded front edges. Nucl. Instrum. Methods Phys. Res. Sect. A-Accel. Spectrom. Dect. Assoc. Equip., 594, 196-201.

12. Hult, M. (2007). Low-level gamma-ray spectrometry using Ge detectors. Metrologia, 44, S87-S94 and: Erratum (2007). Metrologia, 44, 425. (Chapter 1.3.2).

13. Lindahl, P., Hult, M., Cordeiro, F., Gasparro, J., Maquet, A., Marissens, G., \& Kockerols, P. (2007). Improvements in underground gamma-ray spectrometry and the application of measuring radioactivity in agricultural samples. In P. Warwick (Ed.), Environmental radiochemical analysis III (pp. 86-94). UK: Royal Society of Chemistry.

14. Aoyama, M., Tsumune, D., Uematsu, M., Kondo, F., \& Hamajima, Y. (2012). Temporal variation of ${ }^{134} \mathrm{Cs}$ and ${ }^{137} \mathrm{Cs}$ activities in surface water at stations along the coastline near the Fukushima Daiichi Nuclear Power Plant accident site. Geochem. J., 46, 321-325.

15. Aoyama, M., \& Hamajima, Y. (2014). Subduction of Fukushima accident derived radiocaesium in the Pacific Ocean (poster presentation). ICRER2014.

16. Aoyama, M., Tsumune, D., \& Hamajima, Y. (2012). Distribution of ${ }^{137} \mathrm{Cs}$ and ${ }^{134} \mathrm{Cs}$ in the North Pacific Ocean: impacts of the TEPCO Fukushima-Daiichi NPP accident. J. Radioanal. Nucl. Chem., 296(1), 535-539.

17. Aoyama, M., Uematsu, M., Tsumune, D., \& Hamajima, Y. (2013). Surface pathway of radioactive plume of TEPCO Fukushima NPP1 released ${ }^{134} \mathrm{Cs}$ and ${ }^{137} \mathrm{Cs}$. Biogeosciences, 10(5), 3067-3078. 